\title{
On Trying to be With Each Other: A Conversation Between Laura Vriend and Nichole Canuso
}

Laura Vriend, Independent Dance Scholar and Artist, Philadelphia, PA

Nichole Canuso, Director, Nichole Canuso Dance Company, Philadelphia, PA

Conversation recorded in Philadelphia, PA on 25 August 2020, via Zoom

Keywords: Participatory Performance, Philadelphia, Interactive Technologies, Choreographic Improvisation, Zoom, Instructional dances

Laura Vriend: You've been working on this piece Being/With for a while now, you were working on it when the pandemic hit, and you used the video technology in [your earlier piece] Pandæmonium. Could you describe how the piece was to unfold for the audience/participants in the originally planned live version of the piece?

Nichole Canuso: It's an intimate performance for two audience members at a time. Those two audience members are far away from one another geographically. The idea is that eventually those two audience participants will be in two different countries, but for the first iteration they will be in two parts of the same city. There will be two separate installations, one will be in West Philadelphia and one will be in South Philadelphia a few miles apart. The experience of the audience member/participant is that they enter into first a gallery space, a warm up space. Then they enter a small room and in that small room there are a few pieces of furniture and a big screen that shows their own image life sized, through live feed video, so it's almost like a mirror. Through the live feed video, they see themselves walking around that room, but they also see someone else on the screen. They are alone in the room but on the screen, they see themselves interacting with another image: that other image is the other audience member who's in the other space. So, these two people are having a virtual duet on screen. They'll be given instructions about where to sit and how to explore this apparatus, there will be a guide that talks to them [through a headset] and there will be music. Then there's also a chance for them to get to know each other verbally. They're also wearing a microphone and they're prompted to tell each other stories. Then one dancer will enter each space so it eventually becomes a quartet. The dancers are really backgrounding the duet of the two participants. They have a very soft presence and their primary purpose is to elevate the use of the video. The two audience members will 
be new to the experience of navigating the video installation, whereas the dancers will be familiar with it and prepared to take the movements and choices of the audience members and lift them a little bit and amplify them within the context of the video apparatus. The dancers provide subtle guidance and visual suggestion. So those are the elements: the live feed imagery, a verbal conversation and a movement interaction.

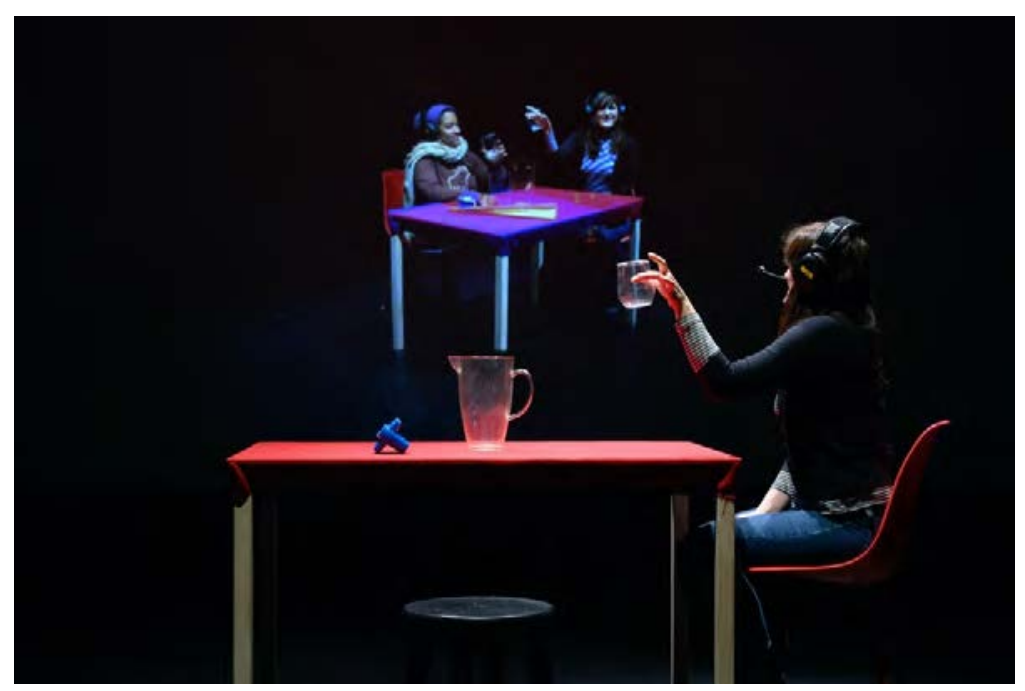

Test audiences in Being/With: Live. Credit: Johanna Austin.

Laura: This piece, which you are now calling Being/With: Live, was originally slated to premiere at the 2020 Philadelphia FringeArts festival. It sounds like there's physical distancing already built into structures of the piece. At what point did you realize that it wasn't going to be feasible to do it this year, that you would premiere it in 2021 and pivot to Being/With: Home on Zoom for 2020?

Nichole: It took a while actually because in some ways, the festival and a lot of the collaborators felt like this was the perfect project to be doing in this moment, because it's an opportunity for people to dance without touching. The heart of this piece is this disorienting sensation of reaching out and seeing yourself hold and touch someone who you're not actually holding and touching, and you're the only person in the room. We started rehearsing online through Zoom so that we could be prepared to build the live show as soon as it was safe to gather again. Eventually we realized that it would not be safe to build the set and risk the health of staff and audience members, and the festival supporting the premiere and the touring grant that was behind the future tours, were both supportive of stretching the timeline of that live premiere. I thought, well if we have the opportunity to wait, why not be as safe as possible? Meanwhile, we were rehearsing it on Zoom, and it was almost like someone dropped a boulder in the highway I was on. I was driving towards Being/With for years, the ideas had been building, it's a very large project as far as the collaborators and the set design, so fundraising took a long time and there's a community outreach section. So, I had this big truck on this big highway and I was almost there and then the boulder dropped and so instead of just sitting there and waiting, we thought let's drive down this side road, let's take a detour and rehearse on Zoom. That detour revealed a beautiful view and 
adventure that I wasn't expecting. That's how the Zoom project felt. It felt like a gift. The center of Being/With: Live was bringing people together through this live feed video technology, which we couldn't do because we can't set that up on everybody's computer. Once that was gone, we still had the conversation between strangers, the instructional dance piece, the movement and the relationship to the guide, so we placed all of that in Zoom and found that there was something quite beautiful about two people doing all of this in their own home instead of a neutral space. It is more vulnerable to move around your home, to conjure memories when you're surrounded by your own objects and to meet someone you've never met and see them move around their home. In a way when we were trying to make this decision about postponing the live version, I started to really mourn letting go of the possibility of doing this on Zoom, which made the decision easier as well. Now we can do both. We can spend a year working on this online piece, which feels very accessible, people who can't leave their homes normally can log in, people from other countries can log in and we have time to feel safe and prepared to do the one we were originally going to do.

Laura: Being/With: Home on Zoom has been running periodically with several different presenting partners since September 2020. Can you describe how the home version unfolds for audience members/participants?

Nichole: In Being/With: Home you log into a Zoom room and we have a lobby designed, a waiting room, with a video and sound installation that will play while you wait. Then a very warm stage manager greets you and teaches you how to use Zoom, so there's an instructional piece that gently guides you to adjust all the settings on your computer so that you only see your own image. Then an audio guide arrives and starts to lead you through some perception exercises, asks you to see your room a little bit differently, asks you to tune into a way of seeing, and a way of experiencing your body that prepares you for the experience. Then you look at your own image and there's some imagery around how you see yourself, who you are now and your ever-changing nature. We bring in themes of water from the outset, seeing yourself as the surface of a lake with currents underneath that cannot be seen. We're asking participants to enter knowing that you're more than anyone will ever know and then when you meet the other person you are also encouraged to understand that they are more than you will ever know. Then you introduce objects to each other from your own home that you have preselected and from there there's a guided journey with the stranger that includes prompted questions that you both answer and time for you to ask follow up questions of one another. Then there's some movement, you're guided through some very simple, gentle movement improvisation instructions that get you communicating non-verbally with the other person in your space and with the screen. Then there's a section where instead of bringing in the two dancers in each space, you each bring in an imaginary person, someone you miss, and so it becomes a quartet between the two of you and the two imaginary memory people. Then there's a final layer of movements and 
questions and answers and then an open space at the end where you can ask each other anything you want. That's the journey.

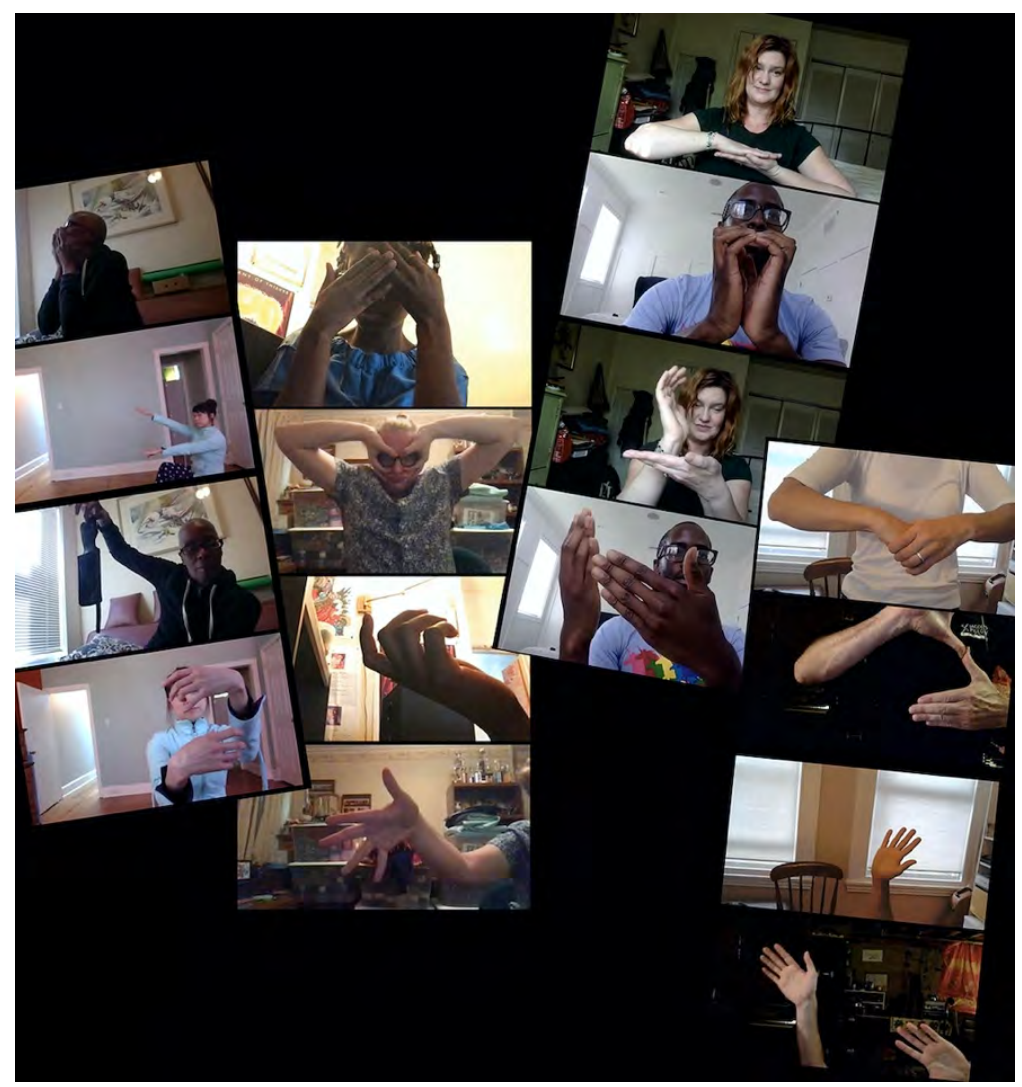

Test audiences in Being/With: Home. Credit: Nichole Canuso.

Laura: I've seen most of your work and there are some overarching themes that I've named for myself. One is this tension between a warmth and delight in intimacy and a loneliness and solitude. Another is a deep interrogation of absence and presence, often with a thread of nostalgia. And formally, the interrogation of absence and presence is explored through, buttressed by and arises from video and audio, technologies that one might typically think of as disembodied forms. These themes: connection, loneliness, and disembodiment seem ripe for exploration during this pandemic. Once that boulder dropped and you went down the side road, what was it like really diving into these themes and these ideas, that had already been such a part of the trajectory of your work, on Zoom in the context of the pandemic?

Nichole: I'll start with something you said that's really insightful and true, which is something in all the work, that feeds everything I do. It comes down to a fascination with the fact that we're all alone in our own experience. We're in the pod of ourselves. But within that is this magical world of imagination and memory and it's infinite and no one can actually understand all of it. No matter how much they love you and how curious they are, they'll never be able to hold all of it. So in that way, we're all alone in our own experience. But in the way that we're all doing that, we're also all connected. So, there's this dichotomy and we can't help but be connected, we can't help but be 
curious. There's this desperate loneliness in the way we're all trapped in our own pod of experience and yet there's this hopefulness around our innate desire to reach past it. We're reaching for something that's completely impossible and yet we reach anyway. So here we are in the pandemic where we're in an exaggerated state of isolation, in our own pod of experience and it starts to feel really small and we start to forget that we have an imagination, we start to forget that we have a past. All we see is the day to day and it feels smaller and more desperate and so this show is asking us to sit across from somebody else who's a stranger and to look past what our first assumptions might be and to remind ourselves that they're going through some version of what we're going through. What if we reach? What if we try? The reaching is even harder because there is no touch and there is no real eye contact, we can try but you can't actually make eye contact. But the trying feels important. We can't touch but we can touch the things in our own space, and there's just this way that we can try for those things that I place high value on like connection and imagination. And maybe the people signing up to do this value those things too, and if not, they're saying yes to trying it with me for an hour. It shed a new light on these themes that were driving all the work to begin with.

Laura: As you know, I was a test audience member for an early version of Being/With: Home. There were two things in particular that struck me. The first one was the sense of taking my home space, which I'd been confined to and so it had taken on a sort of excessive familiarity, and making that space unfamiliar. The second was the efficacy of the sensory strategies for imagining and feeling the presence of people that I missed. I've been video chatting a lot with my family and friends who I'm not able to visit and who I won't see for a long time, but throughout the whole pandemic, this is the thing that made me feel closest to some of those people. How did you conceptualize those strategies and draw from past choreographies to generate these effects?

Nichole: Making the familiar unfamiliar felt really essential. Whenever I make these exploratory works, I make sure that I experience them a lot so I choreograph through doing. Being the audience teaches me what the work needs. In my own body for Being/With: Home, whenever I would look around my room, I would think, oh, we need to acknowledge that we're stuck in here and we need to pour water on it. The sensory strategies had been in place from the beginning with all of these shows, for instance in The Garden ${ }^{1}$ where the goal is to invite people to dance and become part of the choreography, without ever using those words. For people who think that dance is something that's only for certain people and you watch if from afar, how do I subtly, without ever using the word dance, show people that I think we're all choreographers? Another theme is longing, the sensation of missing someone. In Pandæmonium, Geoff [Sobelle] and I are on opposite sides of the stage during the video duet on the screen. There's a yearning that is inherent in the visual set-up. You see these two lone bodies: every time they look at each other in real life they're turning their backs on each other in the video duet and every time they find each other in the video duet, they're turning their backs on each other in real life. While Pandæmonium was being made, my mom 
got really sick and right after it premiered, she passed away. So, being alone/together with Geoff and performing with someone who wasn't actually there suddenly took on enhanced meaning. In Pandæmonium, I'm lying on a table and imagining that I'm putting my arm around Geoff, but he's not there. Just the act of conjuring a body that wasn't there and moving in negative space while losing someone that I really cared about was very therapeutic and very cathartic so I really wanted to explore this with audience members and give them the opportunity to imagine their own relationship to loss and absence and presence. I was really entering this Being/With process thinking about all these things prior to the pandemic. Then when we all started losing the ability to see people we want to see, all of that already existed in the piece. There are already people we've lost or people that are still around but have drifted away from us for one reason or another, and so I was already thinking about that with the main show because it's inherent in the video apparatus that we're playing with. For Being/With: Home, I was trying to explore ways of talking about that that aren't so on the nose, that don't force people if they don't want to. How can we create an invitation where people can go to the depth that they want to in that moment? To replace the dancers, I asked participants to bring these memory people in and that was born out of necessity, but then took the show to a different level: the invitation to invite someone in that you miss and then, have a guided path for what to do with that person and then from there, creating imaginary choreography for you and your person. So, these backpacks were in the car when the boulder fell and when we went down the dirt road, we realized these tools were useful in different, new ways. Oh, that could be a tent, you know, that could be used as this.

Laura: What, if any, kind of choreographic discoveries did you make in working with Zoom? What kept you interested in working with it, learning from it and researching it?

Nichole: I've been working with live feed video for a while, especially in Takes $^{2}$ and Pandæmonium and I was also the performer in both of those. The skill of being in a live space and tracking yourself on a video space is something I had been working on for ten years and I really enjoy sending my brain in those two directions at once. I realized that's actually what I'm asking the audience/participants to do, to really engage with their live space in one part their brain and track themselves on a screen in the other part of their brain so that they could make a dance together in this screen space. I realized the instructions were built around guiding them through that process, using metaphor so it didn't feel tedious. What are the steps to ask of someone who doesn't normally use their space in that way or think about the camera in that way? What are the steps to inviting them to do that without overwhelming them? I had been doing these instruction dances, these headphone dances like The Garden, but they didn't involve video so we had to include the recognition of the camera. What was also interesting was bending to fit any space because in the past we've always designed the space and now the space is changed. Some people are in a tiny closet trying to get away from the rest of the people in their house, some people have a sprawling house with a lot of stuff in 
it and so it's been fun choreographically to watch these duets unfold in very different environments and to script something that can support that.

\section{Biographies}

Laura Vriend is an independent dance scholar and artist in Philadelphia. She holds a PhD in Critical Dance Studies from the University of California at Riverside. Her research has focused on intersecting close readings of site-based choreographies in Philadelphia with social theories of space, spatiality and urbanism to more fully account for how space means in/through dance and performance. She has taught courses in dance and performance studies at the undergraduate and graduate levels at Temple University and at Bryn Mawr College. She has also worked as dramaturge for Megan Bridge/ <fidget> and was a 2019 fellow at Headlong Performance Institute, a supported residency program in Philadelphia. Her current research seeks to intersect dance studies with fat studies to understand how current models for conceptualizing "the body" and "choreography" in both western concert dance practice and the field of dance studies itself do not account for the potential of fat dancing bodies, and have contributed to the consistent and persistent exclusion of fat bodies from the contemporary concert dance stage, even in dance spaces that claim inclusion and purport to embrace all forms of movement as potential choreographic material.

\section{Email: Ivriend@gmail.com}

Nichole Canuso is a choreographer and performer experimenting with the participation of audience bodies and personal narratives through a cross-pollination of artistic mediums. Canuso is dedicated to ensemble-generated processes, aiming to create connections across distances and life experiences. Based in Philadelphia, Canuso founded Nichole Canuso Dance Company in 2004 and is currently a faculty member of the MFA program at The University of the Arts / Pig Iron School for Advanced Performance Training. She is currently exploring the interfaces of live, embodied presence with emerging technologies with a focus on intimate exchanges and the power of listening. Support for her work includes The National Endowment for the Arts, The Knight Foundation, a Bessie Shoenberg First Light Commission, The Pew Center for Arts and Heritage and National Dance Projects/New England Foundation for the Arts. Presentations of her work include New York Live Arts, American Repertory Theater, Los Angeles Performance Practice, Kohler Arts Center, Bates Dance Festival, The Swedish Performing Arts Coalition/Scensverige, Stockholm, Sweden, Festival Internacional de Danza Contemporánea Onésimo, Guadalajara, Mexico. Artistic residencies include Maggie Allessee National Center for Choreography (FL), MacDowell (NH), Millay (NY), 
NCCAkron (OH) and BiLateral Residency (Budapest, Hungary). Nichole is a 2017 Pew fellow and 2021 NEXUS/NYSAF recipient.

Email: nichole@nicholecanusodance.org

Website: nicholecanusodance.org

\section{Notes}

${ }^{1}$ The Garden, Canuso. The Garden is a piece for six audience members at a time who are led via wireless headset through a labyrinthine installation on individual tracks. They are given gentle choreographic directions that invite them into specific choreographies with other audience members as well as more improvisational scores with the cast of performers. See https://nicholecanusodance.org/works/the-garden/ for images.

${ }^{2}$ Takes, Canuso. Takes is a duet that takes place inside a box composed of four translucent screens. Cameras are set up inside the box to capture live feed video of the performers, which is then projected onto all four screens in black and white with a film noir aesthetic. There is often a delay in the projected image so that previous "takes" overlap with live feed to create a sense that the projected bodies are engaging in a duet with each other as well as the live dancers inside the box. See https://nicholecanusodance.org/works/takes/ for images and video.

\section{References}

Being/With: Home. Chor. Nichole Canuso. Perf. Eun Jung Choi, Arielle Colella, Jennifer Kidwell, Rhonda Moore, Guillermo Ortega, Lillian Ransijn, Annie Wilson. USA, 2020. Live work on Zoom.

Pandæmonium. Chor. and Perf. Nichole Canuso and Geoff Sobelle. Dir. Lars Jan. USA, 2016. Live Work.

Takes. Chor. Nichole Canuso. Perf. Nichole Canuso and Dito Van Reigersberg. USA, 2010. Live work.

The Garden. Chor. Nichole Canuso. Perf. Nichole Canuso, Eun Jung Choi, Christy Lee, Scott McPheeters, John Luna, Les Rivera, Annie Wilson. USA, 2013. Live work. 